\title{
Rancang Bangun Aplikasi Knowledge Management Berbasis Web
}

\author{
Yance Sonatha $^{1^{*}}$,Indri Rahmayuni ${ }^{1}$, Alde Alanda ${ }^{1}$, Iswandi Saputra ${ }^{1}$ \\ ${ }^{1}$ Jurusan Teknologi Informasi, Politeknik Negeri Padang \\ *e-mail: yance@pnp.ac.id
}

\begin{abstract}
Abstrak - Manajemen pengetahuan adalah suatu pengorganisasian pengetahuan yang dimiliki oleh individu dalam sebuah organisasi. Dengan manajemen pengetahuan, suatu pengetahuan yang dimiliki individu akan dapat menjadi pengetahuan organisasi sehingga bermanfaat bagi organisasi terutama dalam meningkatkan daya saing bisnis organisasi. Untuk mengelola dan mendokumentasikan pengetahuan sehingga menjadi referensi bagi karyawan dalam perusahaan diperlukan penyusunan dan penerapan sistem manajemen pengetahuan yang tepat. Penerapan sistem manajemen pengetahuan, tentunya harus didukung oleh fitur-fitur yang dibutuhkan untuk menyimpan dan mengorganisasikan pengetahuan yang ada. Untuk mengatasi masalah ini, dirancang sistem manajemen pengetahuan yang dibuat dalam bentuk sistem pemograman berbasis web menggunakan bahasa pemograman PHP dengan Framework GTFW dan MySQL. Sistem manajemen pengetahuan memiliki fasilitas pencarian data dokumentasi, penyimpanan catatan masalah dan informasi berita serta fitur download data dari setiap dokumentasi yang ada.
\end{abstract}

Kata kunci： Framework GTFW, Gamatechno, Manajemen Pengetahuan, MySQL, PHP

\begin{abstract}
Knowledge management is an organization of knowledge held by individuals within an organization. With knowledge management,an individual knowledge can be own by organization so it can give a benefit to organization in order to enhance business competitiveness.Management and documentation of the knowledge in order to become a reference for all the employee within the organization are need a development and implementation of appropriate knowledge management system. The implementation of knowledge management system must be supported by specific features to store and organize the existing knowledge.To overcome this problem, a knowledge management system was designed in the form of a webbased programming system using PHP programming languages with GTFW and MySQL Framework. Knowledge management systems are equiped with data search facilities, documentation and records of problems, information and download features from each of available documents.
\end{abstract}

Keywords: Gamatechno, GTFW Framework, Knowledge Management, MySQL, PHP

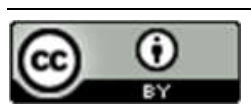

This is an open access article distributed under the Creative Commons 4.0 Attribution License, which permits unrestricted use, distribution, and reproduction in any medium, provided the original work is properly cited. (C2018 by Author and Universitas Negeri Padang

\section{Pendahuluan}

Teknologi dan dan informasi merupakan dua hal yang tidak dapat dipisahkan saat ini. Hal ini terlihat dari proses untuk mendapatkan informasi yang dapat diperoleh secara cepat, tepat, dan akurat dengan didukung oleh kemajuan teknologi yang semakin canggih. Kemajuan teknologi ini membuat banyak instansi, perusahaan, komunitas, dan organisasi menggunakan teknologi berbasis komputer dan jaringan untuk membantu pekerjaanya karena bersifat efektif dan efisien. Dengan kemajuan teknologi juga dapat membantu meningkatkan kinerja suatu perusahaan dalam mencapai tujuan perusahaannya. Hal ini dapat dilihat oleh salah satu perusahaan yaitu PT Gamatechno

Indonesia. PT Gamatechno Indonesia merupakan perusahaan yang memiliki fokus pada pengembangan produk teknologi informasi. Gamatechno juga menyediakan jasa konsultasi IT, audit IT, training IT, serta layanan maintenance sistem dan agregasi konten digital. Seiring dengan perkembangan perusahaan, Gamatechno saat ini berfokus pada pengembangan produk dan solusi teknologi informasi untuk segmen perguruan tinggi, lembaga pemerintah, perusahaan penyedia jasa transportasi dan logistik, serta industri lifestyle. Layanan yang berfokus pada 
4 segmen utama tersebut selanjutnya didefinisikan sebagai gtSmartCity Solution, yaitu solusi berbasis sistem dan teknologi informasi guna mewujudkan sebuah kota cerdas dengan ciri less paper, less time, less cash dan less complexity untuk meningkatkan tatanan hidup masyarakat.

Terjadinya pergantian karyawan pada suatu perusahaan, membuat knowledge yang bersifat individual, akan keluar bersama dengan individu tersebut (knowledge walkout). Proses pergantian karyawan yang baru, mengharuskan perusahaan untuk memberikan pelatihan tambahan sehingga kegiatan tersebut memakan waktu dan biaya yang juga berdampak pada kinerja perusahaan. Bila knowledge yang dimiliki karyawan tidak dikembangkan, maka tidak ada knowledge yang dibagikan untuk dapat dimanfaatkan oleh perusahaan. Knowledge yang sudah dikelola dengan baik dan mudah diakses akan sangat bermanfaat bagi perusahaan karena dapat menghindari kesalahan yang sama. Knowledge harus dipelihara dengan baik, sehingga dapat dikembangkan, diperbaharui dan digunakan terus menerus. Dengan begitu, sebuah perusahaan dapat mengetahui bagaimana langkah-langkah yang tepat dalam menanganin permasalahan dan mengeksplorasi kinerja perusahaan dengan mengedepankan penggunaan informasi yang terstruktur.

Saat ini PT. Gamatechno menyadari pentingnya pengelolaan knowledge untuk menfasilitasi masalah pendokumentasian serta meningkatkan kualitas kerja karyawan. Salah satunya dilihat dalam penggunaan sebuah pendokumentasian dari data dan informasi yang di gunakan untuk keberlangsungan dari kegiatan perusahaan. Hal ini juga dilihat ketika karyawan di PT. Gamatechno Indonesia khususnya tim Project Management Unit (PMU) sebagai tim information technology (IT) di perusahaan dalam mengatasi berbagai masalah yang ditemukan terkait dengan masalah pendokumentasian IT seperti dokumentasi masalah hardware dan dokumentasi masalah software.

Pada PT. Gamatechno Indonesia sistem pengelolaan dokumentasi yang sedang berjalan masih kurang baik. Hal itu disebabkan karena belum adanya sistem yang mengelola dokumentasi tersebut sehingga pendokumentasian yang dilakukan masih bersifat individual, tidak terintegrasi dan struktur penyimpanan yang tidak jelas. Oleh sebab itu, adanya berbagai masalah yang muncul seperti sulitnya menyimpan suatu dokumentasi, susah dalam berbagi dokumentasi antar karyawan, hubungan komunikasi intern yang tidak baik terkait masalah dokumentasi, susahnya dalam melakukan pencarian suatu dokumentasi karena perbedaan lokasi penyimpanan sehingga menyebabkan waktu kerja yang tidak produktif.

Oleh sebab itu dengan adanya 4 segmen fokus yang ada di PT. Gamatechno Indonesia maka akan sangat dibutuhkan suatu sistem yang dapat mengkombinasikan dan mengintegrasikan fungsi-fungsi knowledge yang ada dalam suatu dokumentasi untuk sebuah perlakuan kontekstual terhadap masing-masing segmen tersebut yang dapat digunakan oleh Tim Teknis Project Management Unit PT. Gamatechno Indonesia dalam melakukan pekerjaan teknis nya, maka dibutuhkanlah suatu sistem Knowledge Management System (KMS).

Knowledge Management System (KMS) adalah sistem yang diciptakan untuk memfasilitasi penangkapan, penyimpanan, pencarian, transfer dan penggunaan kembali suatu informasi atau dokumentasi. KMS berfungsi untuk menyediakan dasar nilai bagi perusahaaan, menstimulasi dalam kegiatan manajemen agar fokus pada hal-hal yang penting.

Secara garis besar, aplikasi KMS ini dapat melakukan input data, edit data, hapus data, dapat menampilkan dan mencari data serta mampu menyimpan data-data yang suatu saat dibutuhkan kembali. Aplikasi ini digunakan guna mengatasi masalah-masalah yang sering terjadi di PT. Gamatechno Indonesia terkait pencarian informasi/dokumentasidokumentasi teknis seperti dokumentasi script testing, manual book, user manual, log problem, dokumentasi meeting, dokumentasi training karyawan dan dokumentasi- 
dokumentasi lainnya. Oleh sebab itu dengan adanya aplikasi KMS ini dapat menfasilitasi dalam mengatasi masalah pendokumentasian serta meningkatkan kualitas kerja karyawan. Selain itu, tujuan dari aplikasi KMS ini adalah agar knowledge yang dimiliki setiap karyawan tidak hilang begitu saja dan juga dapat berbagi kepada karyawan lain, serta terciptanya sarana dalam mendiskusikan dan mendistribusikan permasalahan, maupun knowledge yang masih tersimpan dalam setiap karyawan agar tidak terjadinya pengulangan kesalahan-kesalahan yang pernah dilakukan. Hal ini mendorong munculnya ide pembangunan sebuah aplikasi knowledge management system berbasis web yang akan diimplementasikan di PT. Gamatechno Indonesia cabang Jakarta.

\section{StUdi PUSTAKa}

\section{Knowledge}

Knowledge adalah kebiasaan, keahlian, kepakaran, keterampilan, pemahaman atau pengertian yang diperoleh dari pengelaman, latihan atau melalui proses belajar.[1]

Secara umum, para ahli membagi knowledge menjadi dua kelompok besar, sebagai berikut [2] :

1. Tacit Knowledge

Tacit knowledge terletak dalam benak manusia, bersifat sangat proporsional dan sulit dirumuskan. Tacit knowledge mengacu pada knowledge pribadi yang melekat dalam pengalaman individu dan melibatkan faktor-faktor seperti keyakinan, perspektif dan nilai-nilai pribadi.

2. Explicit Knowledge

Explicit knowledge adalah pengetahuan yang dapat diekspresikan dalam bentuk kata, angka, bagan, atau dalam berbagai bentuk dokumentasi seperti prosedur, operasi standar, paper, laporan penelitian, buku, artikel, manuskrip, paten, dan software.

\section{Knowledge Management}

Menurut Nonaka, knowledge management cycle terdiri dari empat komponen seperti terlihat pada Gambar 1 berikut : [3]

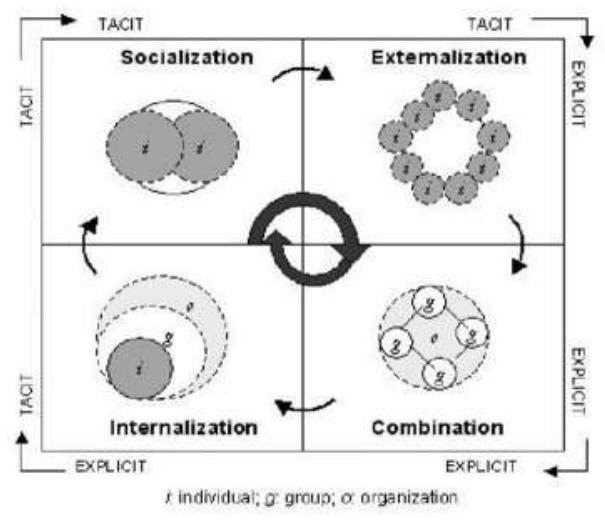

Gambar 1. Knowledge Management Cycle [3]

\section{Sosialization}

Tacit knowledge ke tacit knowledge disebut proses sosialization. Transfer knowledge dari satu individu ke individu lainnya dalam bentuk tacit knowledge. Disebutkan bahwa socialization muncul dari aktivitas berbagi dan menciptakan pengetahuan tacit melalui pengalaman langsung.

\section{Externalization}

Tacit knowledge ke explicit knowledge disebut proses externalization. Externalization merupakan proses menyajikan tacit knowledge ke dalam bentuk yang lebih mudah untuk dikomunikasikan dan dimanfaatkan. Dalam prakteknya, externalization didukung oleh dua faktor, yaitu konversi dari tacit ke explicit dan menerjemahkan pengetahuan tacit dari para ahli kedalam bentuk yang dapat dipahami, misalnya dokumen.

3. Combination

Proses explicit knowledge ke explicit knowledge disebut dengan proses combination. Combination merupakan perpaduan pengetahuan eksplicit dengan pengetahuan explicit lainnya untuk membentuk suatu pengetahuan yang lebih mudah dipahami.

4. Internalization

Explicit knowledge ke tacit knowledge disebut proses internalization. Internalization merupakan proses pembelajaran dan penerapan dari explicit knowedge untuk memunculkan atau menghasilkan knowledge yang baru atau memperbaharui knowledge yang ada. 
Core knowledge adalah pengetahuan utama perusahaan yang bertujuan dalam membantu untuk mencapai tujuan dari perusahaan, seperti: [4]

1. Mendukung fokus dan kegiatan utama dari perusahaan.

2. Memiliki nilai jangka panjang pada kegiatan perusahaan.

3. Memberikan performa lebih dalam kegiatan utama perusahaan.

4. Meminimalkan kegiatan yang berulang atau salah pada anggota perusahaan.

Core knowledge dalam perusahaan selalu berubah seiring dengan perkembangan perusahaan tersebut. Banyak perusahaan gagal dalam menentukan pengetahuan apa yang penting dalam bisnisnya, sehingga perusahaan tidak dapat memaksimalkan pengetahuan yang ada.[5]

\section{Knowledge Management System}

Knowledge management keberhasilan menggunakan kembali pengetahuan untuk meningkatkan efektivitas organisasi dengan memberikan pengetahuan yang tepat untuk mereka yang membutuhkannya ketika dibutuhkan kembali.[1]

Knowledge management memiliki tiga elemen penting yaitu people, process dan technology seperti terlihat pada Gambar 2. Ketiga elemen tersebut merupakan komponen yang dapat mempengaruhi keberhasilan implementasi knowledge management. Knowledge management merupakan integrasi ketiga komponen tersebut dengan budaya organisasi.[6]

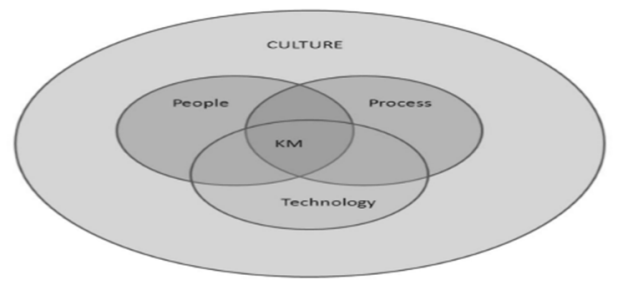

Gambar 2. Komponen Knowledge Management[6]

Knowledge Management System adalah cara untuk mencapai tujuan dari knowledge management yang diterapkan oleh perusahaan dan kelompok industri dengan menggunakan teknologi informasi. Knowledge Management System mencakup beberapa kondisi hard environment seperti peralatan teknologi informasi, dan serangkaian kondisi soft environment seperti sistem organisasi.[5]

\section{METODE}

Pengembangan aplikasi ini merujuk pada metode waterfall yang bisa terlihat pada Gambar 3 berikut :

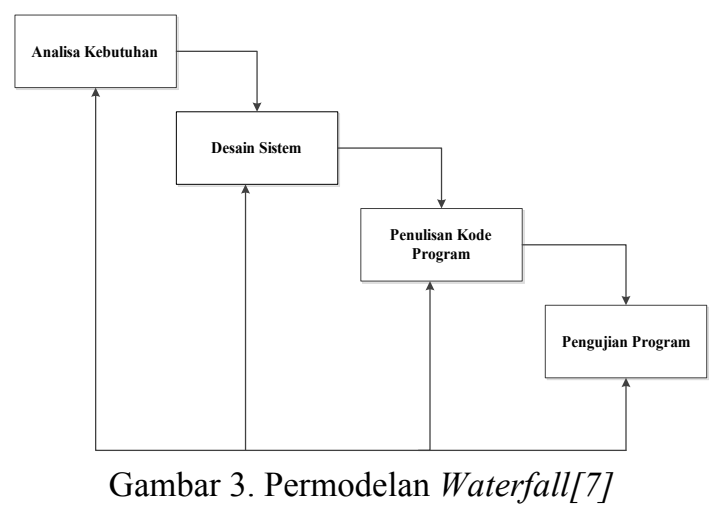

Tahapan metodologi tersebut sebagai berikut :

1. Analisis Kebutuhan

Tahapan ini bertujuan untuk menganalisis kondisi dan mendeskripsikan kebutuhan user terhadap pentingnya sistem yang akan dibangun.

2. Desain Sistem

Proses desain bertujuan untuk merancang atau membuat suatu aplikasi. Hal ini meliputi perancangan antarmuka aplikasi. Desain menggunakan UML yang terdiri dari use case diagram, class diagram, activity diagram dan sequence diagram. Tahap ini mengubah kebutuhan aplikasi dari tahapan analisis kebutuhan ke representasi desain agar dapat diimplementasikan pada tahap selanjutnya

3. Pembuatan

Merupakan penerjemahan design sistem kedalam bahasa pemograman. Pada tahapan ini difokuskan pada pembuatan sistem sesuai dengan desain yang ada.

4. Pengujian Program

Tahapan ini merupakan tahap akhir dari pembuatan sebuah sistem. Setelah melakukan analisa kebutuhan user, design, 
pembuatan, maka sistem dijalankan dan dilihat apakah ada kesalahan atau tidak.

\section{HASIL DAN PEMBAHASAN}

\section{Analisis Kebutuhan}

Analisis kebutuhan bertujuan untuk mengetahui permasalahan yang ada sehingga mendapatkan suatu hasil dari permasalahan tersebut. Berdasarkan hasil observasi dan wawancara maka dapat di identifikasikan suatu kelemahan-kelemahan dari sistem knowledge management yang sedang berjalan pada PT. Gamatechno Indonesia tersebut, antara lain:

a. Adanya sistem dokumentasi yang masih manual menyebabkan sulitnya mencari data-data yang diperlukan karena banyaknya dokumentasi yang tidak terstruktur sehingga memakan waktu yang lama.

b. Proses pencarian dokumentasi dengan memakan waktu yang lama menyebabkan kesalahpahaman antar karyawan bagian teknis yang menghambat kelancaran proses kerja antar karyawan.

c. Adanya kesulitan untuk meningkatkan knowledge karyawan, serta kurangnya kesadaran untuk membangun individu yang memiliki knowledge. Selain itu perusahaan juga harus mengeluarkan biaya ekstra untuk memberikan pelatihan-pelatihan bagi karyawannya.

d. Banyaknya pengetahuan yang hilang pada saat karyawan meninggalkan perusahaan dikarenakan karyawan tersebut pindah tugas, resign, ataupun pensiun.

e. Adanya kesalahan-kesalahan yang ditemukan dalam pencatatan log problem oleh karyawan IT.

f. Terjadinya pengulangan kesalahan pada saat menghadapi suatu yang sulit, karena tidak adanya pendokumentasian dari permasalahan yang terjadi berserta solusinya, sehingga perusahaan mengalami banyak kehilangan waktu, tenaga dan biaya yang seharusnya tidak terulang kembali.

g. Hasil meeting yang telah dicapai seringkali terlupakan dalam waktu yang singkat, sehingga menyebabkan pelaksanaan hasil rapat tidak sesuai dengan yang semestinya. h. Tidak ada wadah penyampaian ide karyawan yang berguna bagi perusahaan.

i. Tidak ada wadah penyimpanan dan pengelolaan semua pengetahuan yang sangat berguna bagi perusahaan.

j. Data log problem yang tidak terkelola dan tersimpan dengan baik menyebabkan karyawan IT akan kesulitan dalam menyimpan dan mencari log problem ketika dibutuhkan

Setelah di analisis secara keseluruhan, maka perlu dilakukan pengembangan sistem agar manajemen pengetahuan di PT. Gamatechno Indonesia lebih baik dari sistem yang sebelumnya. Tabel 1 menjelaskan spesifikasi kebutuhan fungsional dan non fungsional untuk pembangunan aplikasi.

Tabel 1. System Requirement Specification

\begin{tabular}{|c|c|}
\hline $\begin{array}{l}\text { SRS } \\
\text { ID }\end{array}$ & Deskripsi \\
\hline 01 & 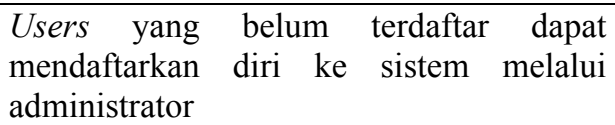 \\
\hline F02 & $\begin{array}{l}\text { User dapat melakukan pengolahan data } \\
\text { employee profile dan data company profile }\end{array}$ \\
\hline F03 & $\begin{array}{l}\text { User dapat melakukan pengolahan data } \\
\text { dokumentasi } \\
\text { dokumentasi } \\
\text { meeting,dll) }\end{array}$ \\
\hline F04 & $\begin{array}{l}\text { Users dapat mencari isi dari suatu file } \\
\text { dokumentasi }\end{array}$ \\
\hline F05 & Users dapat mengisi data log problem \\
\hline F06 & $\begin{array}{l}\text { Users dapat melihat dan mengetahui data } \\
\text { news }\end{array}$ \\
\hline F07 & $\begin{array}{l}\text { Users dapat mengunggah dokumentasi } \\
\text { produk, training dan meeting }\end{array}$ \\
\hline F08 & $\begin{array}{l}\text { Users dapat mengunduh dokumentasi } \\
\text { produk, training dan meeting }\end{array}$ \\
\hline F09 & $\begin{array}{l}\text { Administrator dapat mengelola sistem } \\
\text { secara keseluruhan }\end{array}$ \\
\hline NF01 & $\begin{array}{l}\text { Adanya penggunaan password dalam form } \\
\text { login untuk membedakan tipe users } \\
\text { termasuk hak akses tiap users }\end{array}$ \\
\hline NF02 & Dapat diakses client dari berbagai browser \\
\hline
\end{tabular}

\section{Desain Sistem}

Untuk menjawab permasalahanpermasalahan yang dihadapi dalam pengimplementasian sistem tersebut, maka diusulkan perancangan suatu aplikasi Knowledge Management System (KMS) yang dapat diakses melalui website. Gambar 4 
berikut memperlihatkan use case diagram dari sistem yang akan dikembangkan.
Dalam use case diagram tersebut dapat dilihat ada 2 jenis actor yang terlibat yakni administrator dan user.

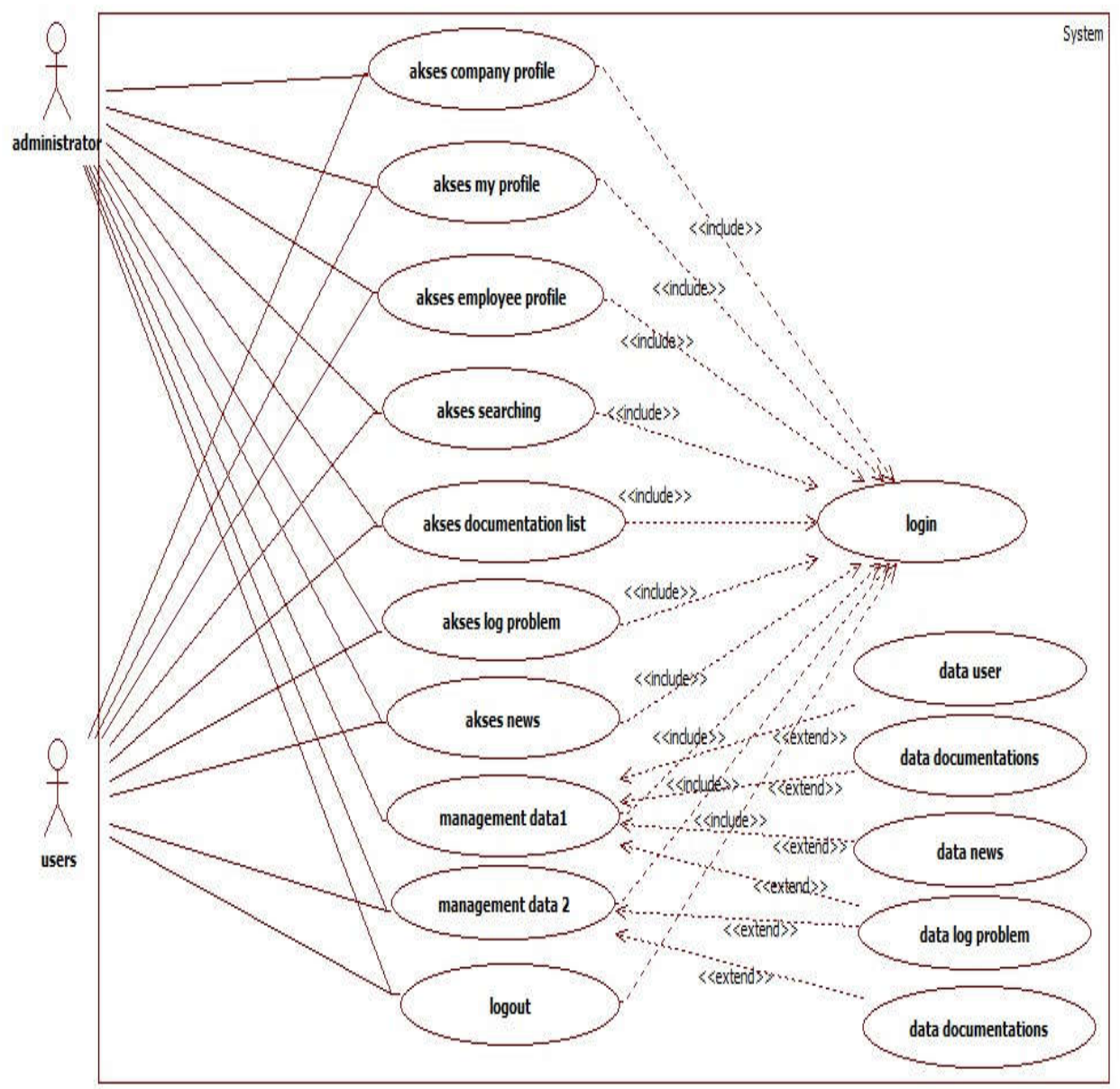

Gambar 4. Use Case Diagram KMS

\section{Pembuatan Sistem}

Untuk menggunakan aplikasi Knowledge Management System dibutuhkan beberapa software yaitu :

1. Implementasi Sistem Melalui Browser

Sistem yang telah dibuat dijalankan pada sebuah browser. Salah satu browser yang digunakan pada implementasi aplikasi Knowledge Management System ini adalah UC Browser.

2. Implementasi konversi file dari extensions .doc, .docx, .pdf, .xlsx, .xls dan .pptx ke extension .txt

File-file yang telah di upload kan dalam fitur dokumentasi pada aplikasi Knowledge Management System akan di konversikan ke file dengan extensions .txt agar isi file tersebut dapat ditemukan pada saat melakukan pencarian di fitur searching. Aplikasi-aplikasi yang berperan dalam mengkonversikan jenis file tersebut adalah antiword, docx2txt, pdf2txt, pptx2txt dan xlstocsv.

3. Implementasi Output Word, Pdf, Powerpoint, Excel dan Image

Data aplikasi Knowledge Management System yang telah di input ke database dapat di download pada sistem. Hasil output data tersebut dapat berbentuk sebuah file word, pdf, powerpoint, excel dan image.

Gambar 5 berikut memperlihatkan tampilan halaman login dari aplikasi KMS yang diakses melalui software UC browser. 


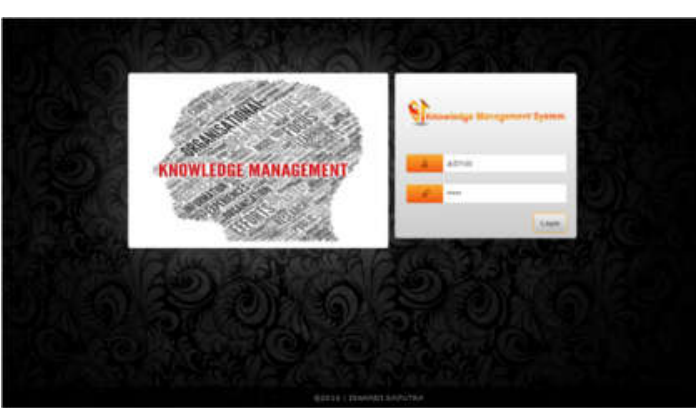

Gambar 5. Halaman Login

Setelah user berhasil login, maka akan keluar tampilan awal seperti terlihat pada Gambar 6 berikut ini.

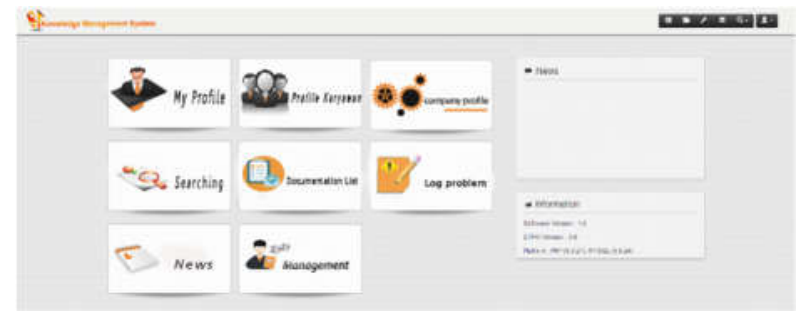

Gambar 6. Halaman Utama Setelah Login

Halaman seperti pada Gambar 7 ini adalah halaman yang tampil jika users atau administrator memasukkan data login yang benar, maka akan di arahkan ke halaman utama aplikasi KMS. Pada halaman tersebut terdapat 8 menu yang bisa dilakukan users atau administrator, yakni menu My profile, Employee profile, Company profile, Searching, Documentation list, Log problem, News dan Management.

\section{Pengujian}

1. Pengujian Input Data User

Gambar 7 memperlihatkan form penambahan user. Data user bisa ditambahkan oleh administrator sistem. Administrator harus mengisi kelengkapan data user.

Ketika administrator telah selesai menginputkan data user maka pada saat melakukan penyimpanan akan tampil informasi bahwa data tersebut sukses disimpan kedalam sistem. Informasi nya dapat dilihat seperti pada Gambar 8 .

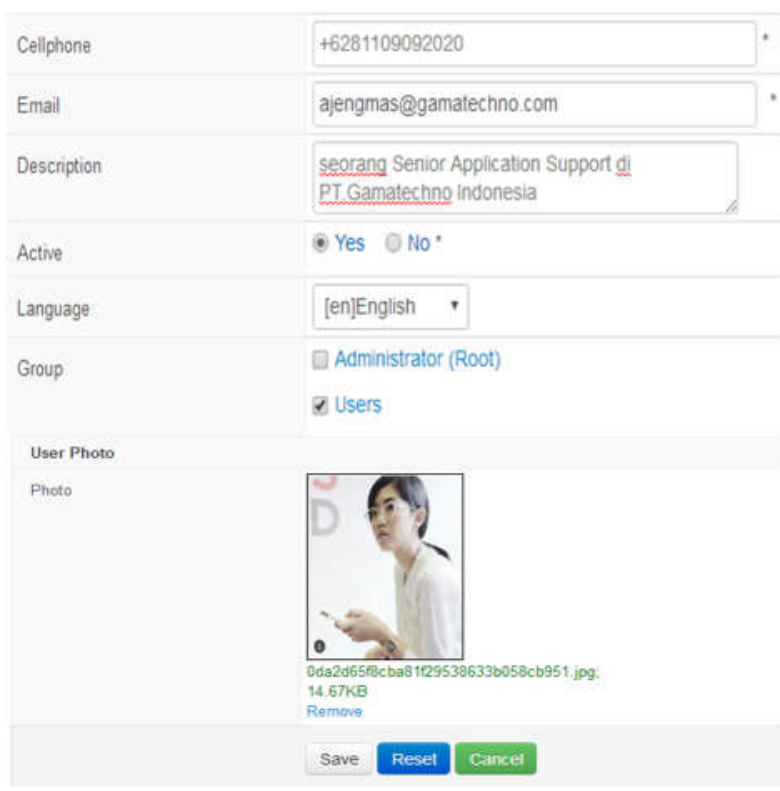

Gambar 7. Tampilan Add Data Pengguna

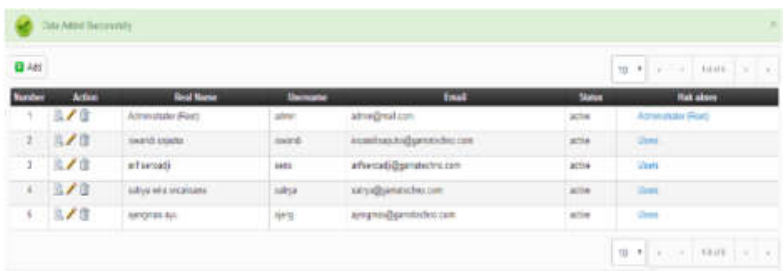

Gambar 8. Tampilan Informasi Data Berhasil Ditambahkan

2. Pengujian Pencarian Dokumen

Ketika pengguna melakukan pencarian dokumentasi pada menu searching, jika keyword yang diinputkan sesuai dengan isi file data yang ada pada sistem maka akan tampil informasi data yang dicari tersebut dan pengguna juga dapat melakukan perintah open file seperti yang terdapat pada Gambar 9 berikut.
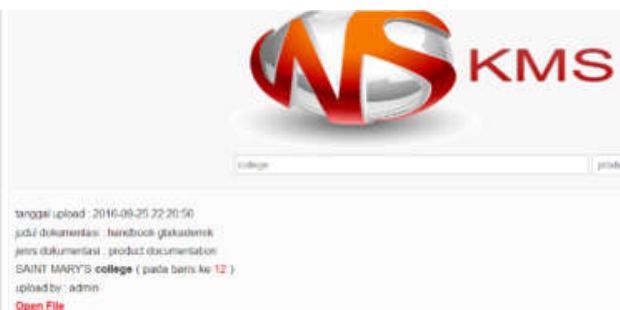

Gambar 9. Halaman Data Searching Ditemukan

Ketika pengguna melakukan pencarian dokumentasi pada menu searching, jika keyword yang diinputkan tidak sesuai dengan isi file data yang ada pada sistem 
maka akan tampil informasi bahwa data yang dicari tidak ditemukan seperti yang terdapat pada Gambar 10 berikut.

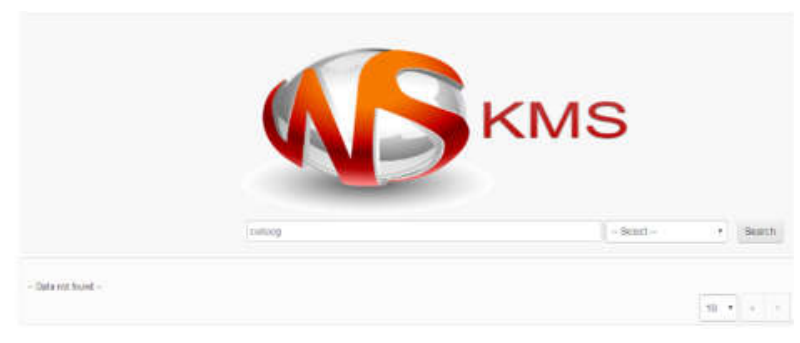

Gambar 10. Halaman Data Searching Tidak Ditemukan

\section{KESIMPULAN}

Berikut ini beberapa kesimpulan yang dapat ditarik dari proses pengembangan KMS. Pertama aplikasi Knowledge Management System telah berhasil dikembangkan dan terbukti dapat membantu dan mempermudah pengolahan data dokumentasi IT di PT. Gamatechno Indonesia seperti dokumentasi produk, dokumentasi rapat dan dokumentasi pelatihan. Selain itu aplikasi Knowledge Management System juga ini dapat membantu karyawan IT dalam membuat menyimpan data log problem dan karyawan IT dapat dengan mudah mencari dan mengunduh dokumentasidokumentasi yang terdapat di dalam Aplikasi Knowledge Management System.

\section{DAfTAR PUSTAKa}

[1] Jennex, M.E.(2007), "What is Knowledge Management?" International Journal of Knowledge Management, Vol 1, No 4, pp. i-iv

[2] Munir N. 2008. Knowledge Managemen Audit: Pedoman Evaluasi Kesiapan Organisasi Mengelola Pengetahuan. PPM Jakarta.

[3] Nonaka, Ikujiro \& Takeuchi, Hirotaka . 2000. The Knowledge-Creating Company: How Japanese Companies Create the Dynamics of Innovation. Oxford: Oxford University Press.

[4] Shelda Debowski, (2006). Knowledge Management. Melbourne and Sydney: John wiley and Son Australia, Ltd.
[5] Chen, Z., Xu, X. (2010). Study on Construction of Knowledge Management System Based on Enhancing Core Competence of Industrial Clusters. International Journal of Business and Management, 5(3), 217-222

[6] Collison, C and Parcell, G 2001, Learning to fly, Capstone, UK.

[7] Roger S, Pressman. 2010.Software Engineering : a Practitioner's Approach 7th Edition. New York:McGraw-Hill.

[8] Pudjo, Prabowo Widodo, Herlawati. (2011). Menggunakan UML. Bandung: Informatika Bandung.

[9] Arief, M.Rudianto(2011d:152). 2011. Pemrograman Web Dinamis Menggunakan Php dan Mysql. Yogyakarta: ANDI.

[10] Dennis, Alan. Wixom, Barbara Haley. Tegarden, David. System Analysis and Design with UML An Object-Oriented Approach. Wiley. 2010.

\section{BiodataPenulis}

Yance Sonatha, adalah salah satu pengajar aktif di Jurusan Teknologi Informasi Politeknik Negeri Padang. Menamatkan kesarjanaan di Program Studi Ilmu Komputer FMIPA Universitas Gadjah Mada tahun 2004 dan Magister Informatika di STEI Institut Teknologi Bandung.

Indri Rahmayuni, menyelesaikan Sarjana Teknik pada tahun 2006 dari Institut Teknologi Bandung dan kemudian melanjutkan ke jenjang Magister Teknik ditempat yang sama dan lulus pada tahun 2011. Sejak tahun 2008 sudah tercatat aktif menjadi pengajar di Jurusan Teknologi Informasi Politeknik Negeri Padang.

Alde Alanda menyelesaikan Diploma Teknik Komputer Politeknik Negeri Padang pada tahun 2009 dan Sarjana Komputer dari Universitas Putra Indonesia tahun 2011. Kemudian melanjutkan ke jenjang Magister Teknik di Institut Teknologi Bandung dan lulus pada tahun 2013. Sejak tahun 2015 tercatat aktif sebagai pengajar di Jurusan Teknologi Informasi Politeknik Negeri Padang.

Iswandi Saputra adalah alumni Program Studi Manajemen Informatika Politeknik Negeri Padang. Saat ini sudah bekerja sebagai programmer di salah satu perusahaan swasta. 